\title{
TUBEROUS SCLEROSIS - A CASE REPORT
}

\author{
Ali M$^{1}$, Zeba-Un-Naher ${ }^{2}$, GM Faruk Hossain ${ }^{3}$, Zahida Zabber ${ }^{4}$, Shafiqul Islam ${ }^{5}$
}

\begin{abstract}
The aim of this case report was to present a typical case of tuberous sclerosis. On 28 April 2012 a 8 year old female student reported as out patient of Ophthalmology Department, BSMMU, Dhaka. After taking history from the patient, ocular and systemic examinations were done. This patient had recurrent attacks of convulsion since 2 months of age and blurring of vision for 3 months. Ocular examination revealed fundus astrocytomas and patchy iris hypo-pigmentation. Systemic examination present with adenoma sebaceum. For diagnosis purpose, she was advised for investigation. CT scan of brain-Multiple cerebral calcification with bilateral multifocal cerebral atrophy. USG of whole abdomen-suggestive of cystitis. Methodical ocular and systemic examinations with appropriate investigations are mandatory to diagnose a case of tuberous sclerosis.
\end{abstract}

Keywords: Tuberous sclerosis.

\section{INTRODUCTION}

Tuberous sclerosis is a neurocutaneous syndrome with an autosomal dominant inheritance. Tuberous sclerosis has an approximate incidence of one in ten thousand to fifty thousand. The clinical triad of papular facial nevus, seizures and mental retardation is found in less then half of the patient. Thus the radiological hallmarks of this neurocutaneous syndrome are universally accepted as sufficient for diagnosis. ${ }^{1}$ This autosomal dominant (AD) condition present with hamartomas affecting many systems. The classic triad of clinical features comprises mental retardation, epilepsy and skin lesions but not all are invariable present. ${ }^{2}$ Tuberous sclerosis (Bourneville disease) is an AD phacomatosis characterized by the development of hamartomas in multiple organ systems from all primary germ layers. The classic triad of epilepsy, mental retardation and adenoma sebaceum is only present in a minority of patients, but is diagnostic. About $60 \%$ of cases are sporadic and $40 \%$ are AD. Cutaneous signs- (1) adenoma sebaceum, consisting of fibroangiomatous red papules with a butterfly distribution around the nose and cheeks, is universal; (2) ash leaf spots are hypopigmented macules on the trunk; (3) Shagreen patches; (4) Fibrous plaques on the forehead; (5) Skin tags; (6) cafe-au-lait spots; and (7) subungual hamartomas. Neurological features- (1) intracranial paraventricular subependymal astrocytic nodules and giant cell astrocytic hamartomas; (2) mental retardation; and (3) Seizures. Visceral tumours- (1) Renal angiomyolipomas and cysts; and (2) cardiac rhabdomyomas. Ocular features apart from fundus astrocytomas, include patchy iris hypopigmentation and atypical iris colobomas. ${ }^{3}$ Two types of hamartomas found in the retina are: (1) relatively flat and soft appearing white or grey lesions usually seen in the posterior pole; and (2) large nodular tumours having predilection for the region of the optic disc. ${ }^{4}$

\footnotetext{
Medical Officer, Department of Ophthalmology, BSMMU, Dhaka. Medical Officer, Department of Biochemistry, BSMMU, Dhaka. Assistant professor, Department of Ophthalmology, BSMMU, Dhaka. Consultant, Department of Ophthalmology, BSMMU, Dhaka.

Professor, Department of Ophthalmology, BSMMU, Dhaka.
} 


\section{CASE PRESENTATION}

History of Present Illness: According to the patient's mothers statement,she was alright after her birth.since 2 months of age she suddenly developed convulsion which was recurrent, occurs $1 / 2$ days intervale, persists for few seconds \& after the attack she became normal,takes her feed with normal body movement. For this they consult with a doctor in Dhaka Shjshu Hospital who advised syp sodium valproit for 3years.But after 2 years as she remains seizure free she stopped the drug \& remain symptom free for another 2 years. During this period (2m-3yrs) her physical \& mental development was alright. At 3 years of age she develoved acne like skin lesion in cheeks, other types lesion in trunk. When she was 5 years old she again developed seizure which was also recurrent,increased in frequency, persists for several minutes, associated with salivation,urinary incontenance \& semiconciosness. Meanwhile her skin lesions become more extensive, her Behavour changed (aggressive) \& withdrawn from school. At her 7 years they again consult in center for neurodevelopment in BSMMU \& start anticonvulsant drugs. For last 3 months she complaints of blurring of vision B/E without associated with other ocular symptoms \& referred to ophthalmology dept BSMMU for ocular evaluation. Nothing significant for past illness. She had a drug history of Anticonvulsant (Na-valproate). General examination found, she was restless, lack of attention but cooperative. She had- pulse: 88 b/min; Body build: Average; Decubitus: on choice; BP 1oo/55mm of Hg; Weight: 38 kg; Temperature: normal; Anaemia: Mildly anaemic; Skin: charecteristic skin lesions(Adenoma sebaceum,Shagreens patch,Ash leaf spot). Other general examination revealed normal.
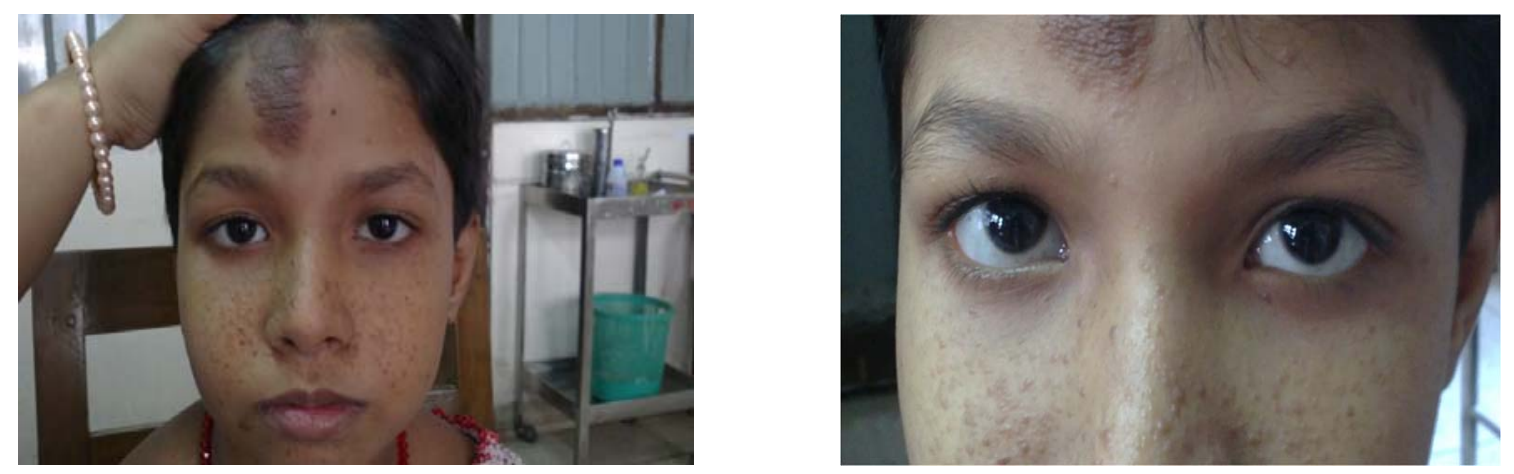

Fig. 1: Adenoma sebaceum

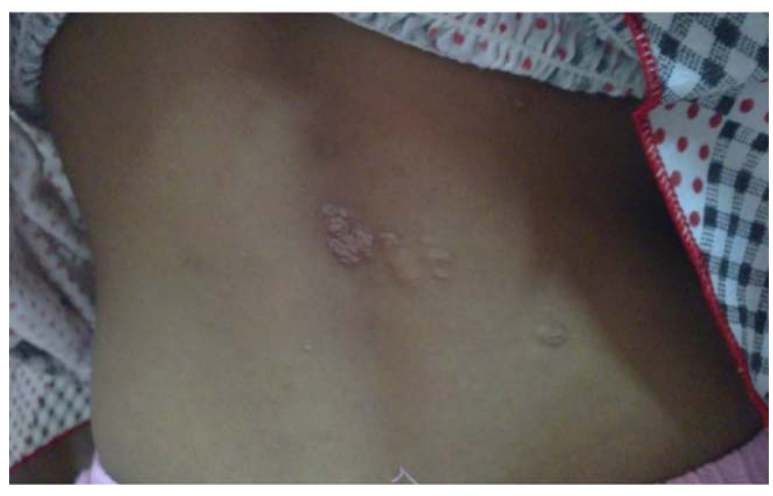

Fig. 2: Shagreen Patches

Ocular examinations: Local examinations showed no facial abnormality is noted, puncta is normal, no redness, tenderness is noted in lacrimal sac area and visual acuty of both eye was 6/12. Pupillary 
light reaction, RAPD, hirschberg reflex, ocular motility was normal. Slit lamp examination showed normal eye lids and lashes, conjunctiva, cornea, ant. chamber, pupil and lens. Iris were slightly hypopigmented. Fundus examination:

\begin{tabular}{|l|l|l|}
\hline \multicolumn{1}{|c|}{ R/E } & \multicolumn{1}{c|}{ L/E } \\
\hline Media & Clear & Clear \\
\hline Background & Multiple white spots & Multiple white spots \\
\hline Disc & $\begin{array}{l}\text { Normal in Size and shape with clear cut } \\
\text { margin }\end{array}$ & $\begin{array}{l}\text { Normal in Size and shape with clear } \\
\text { cut margin }\end{array}$ \\
\hline C:D & 0.3 & 0.3 \\
\hline Blood vessels & Normal & Normal \\
\hline Macula & Healthy & Healthy \\
\hline Foveal Reflex & Dull, dark spot in foveal region & Dull,dark spot in foveal region \\
\hline
\end{tabular}

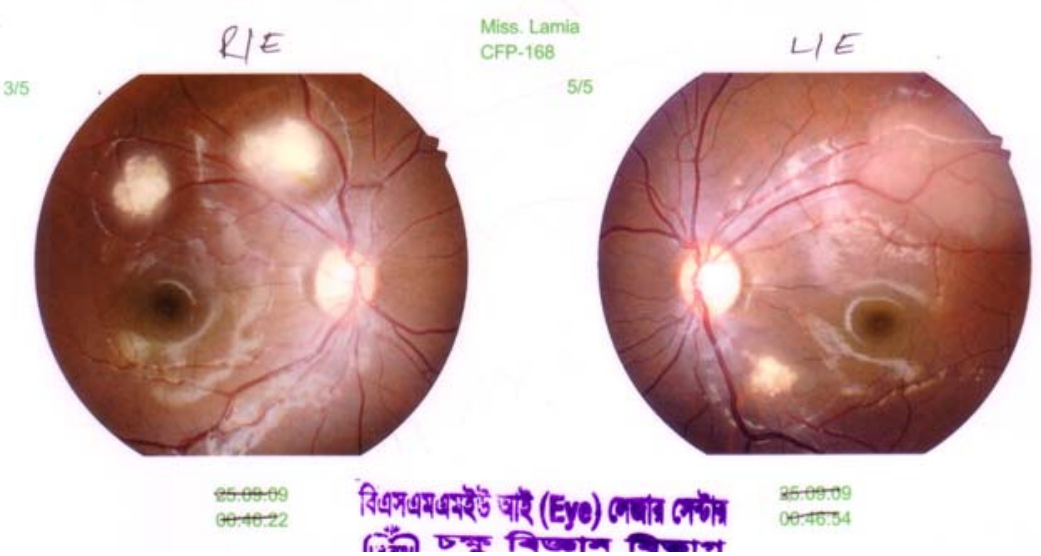

Fig. 3 : Fundous presented with Multiple white spots and Dull, dark spot in foveal region

Systemic examinations: Respiratory system was normal when examined. Cardiovascular system arterial pulse 76 b/min, regular, blood pressure 100/60 mm of Hg, neck veins normal. Gastrointestinal system was normal. Nervous system was Higher Psychic Funtion: Mentally retarted; Cranial Nerves: Intact; Motor function: Slight weakness on Rt/s; Sensory function: Intact; Reflex : Diminished

\section{Invertigations}

- EEG-partial seizire(mesial temporal lobe epilepsy)

- CT scan of brain-Multiple cerebral calcification with bilateral multifocal cerebral atrophy.

- USG of whole abdomen-suggestive of cystitis. 


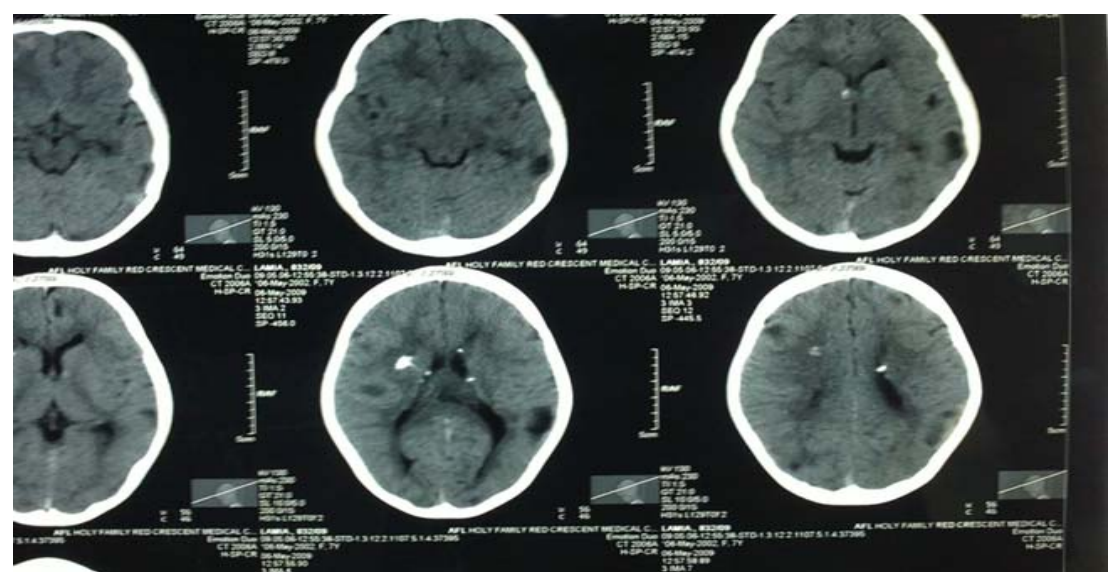

Fig. 4: CT scan brain showed multiple cerebral calcification with bilateral multifocal cerebral atrophy.

\section{DISCUSSION}

"Tuberous sclerosis" was first described in eighteen hundred eighty by Bourneville ( a french physician) . The neurocutaneous syndrome is named for the firm whitish tuber like nodules arising from the cerebral convolutions. The most frequently involved organs are brain, kidneys, lungs, heart, skin and skeleton. In present case Miss Lamia 8 years girl developed recurrent seizure at 2 months of age \& remained symptom free with treatment having normal physical \& mental growth upto 3 years. At 3 years of age she developed various types of skin lesions which gradually increasing with behavioral abnormality. At the age of 5 years she again developed seizure with increasing frequency and time associated with salivation, urinary incontinance and semiconciosness. For this again start treatment again after consultation in BSMMU \& seizure now controlled. Classical CNS involvement includes cortical tubers, subependymal nodules, subependymal giant cellastrocytoma and benign white matter lesions. Tubers are benign lesions composed of dysmorphic neurons occupying a cortical or subcortical location. They are detected by abnomal signal on M.R. or due to distortion of affected gyrus. Cortical tubers may calcify. By age ten, fifty percent of patients have calcified cortical tubers. ${ }^{5}$

For last 3 months she complaints of blurring of vision without any other ocular symptoms. On G/E-she is restless, inattentive and have variou types of charecteristic skin lesionss (adenoma sebsceum, shegeens patch, ashleaf spots) in multiple sites. Ocular examination shows-VA-6/12 B/E, fundus B/Eshows multiple white spots, dull fovel reflex B/E, atrophy, cupperwireing in L/E. Ocular features apart from fundus astrocytomas, include patchy iris hypopigmentation and atypical iris colobomas. ${ }^{3}$ Two types of hamartomas found in the retina are: (1) relatively flat and soft appearing white or grey lesions usually seen in the posterior pole; and (2) large nodular tumours having predilection for the region of the optic disc. ${ }^{4}$

On Invertigations we found EEG-partial seizire(mesial temporal lobe epilepsy) CT scan of brainMultiple cerebral calcification with bilateral multifocal cerebral atrophy. USG of whole abdomensuggestive of cystitis. These findings were not well matched with several studies, Patel et al. 2004 found tuberous sclerosis presented with: USG of abdomen showed enlarged kidneys, the parenchyma of which was completely replaced by multiple echogenic lesions which was suggestive of angiomyolipomas, liver showed presence of haemangiomas and CECT brain showed presence of a large heterodense space-occupying lesion with internal calcification near the foramen of monro. It showed inhomogenous contrast enhancement with proximal obstructive hydrocephalus. ${ }^{6}$ The 
autosomal dominant disease, 'Tuberous sclerosis' could be varied with presentation, so its diagnosis needs methodical ocular and systemic examinations with appropriate investigations are mandatory to diagnose a case of tuberous sclerosis.

\section{CONCLUSION}

This autosomal dominant condition present with hamartomas affecting many systems. The classic triad of clinical features comprises mental retardation, epilepsy and skin lesions but not all are invariable present. Thus knowledge of various associations of tuberous sclerosis can be helpful in

retrogradely establishing the diagnosis. The above point has been emphasized by the cases reported here.

\section{REFERENCES}

1.Braffman BH, Bilaniuk CT, Zimmerman RA. 'MR of central nervous system neoplasia of the phakomatoses’, Sem Roentgenol, 1990; 25: 198-217.

2.Schofield OMV and Rees ZL. 'Skin disease', Boon NA, Colledge NR, Walker BR and Hunter JAA. Davidsons principles \& Practice of Medicine, $20^{\text {th }}$ ed. Churchill Livingstone Elsevier, Philadelphila USA, 2006: 1307-1308.

3.Kanski JJ, Bowling B, Nischal K and Pearson A. 'Ocular tumours', Gabbedy R and Cook L, Clinical Ophthalmology- A systematic Approach, $7^{\text {th }}$ ed. Elsevier, Saunders, UK, 2011: 518-520.

4.Khurana AK. 'Diseases of the Retina', New age international (P) Ltd., Comprehensive Ophthalmology, $4^{\text {th }}$ ed. New Age International, New Delhi, India, 2007: 285.

5.Kingsley D, Kendall B, Fitz C. 'Tuberous sclerosis: a clinicoradiological evaluation of 110 cases with particular reference to atypical presentation’, Neuroradio, 1986; 28: 171- 190.

6.Patel SB, Shah SS, Goswami K, Shah N, Pandhi S. 'Case report: Tuberous sclerosis - it's varied presentation', Indian J Radiol Imaging, 2004; 14: 423-5 